\title{
Synthesis of $\mathrm{ZnMn}_{2} \mathrm{O}_{4}$ nanoplates as anode materials for lithium ion
}

\section{batteries}

\author{
Hao Zheng ${ }^{a}$, Qing Liu ${ }^{b}$, Ting Wang ${ }^{c}$, Jinsong Cheng ${ }^{d}$, Rongfei Zhao ${ }^{e}$, Lin Li $^{f}$ \\ Key Laboratory of Functional Materials and Chemistry for Performance and Resource of Guizhou \\ education department, Anshun University, Anshun 561000, China \\ azhengaho1986@126.com, b496063041@qq.com, '390516278@qq.com, d85828082@qq.com, \\ e44723318@qq.com, 'tilin404003375@qq.com
}

Keywords: $\mathrm{ZnMn}_{2} \mathrm{O}_{4}$, nanoplates, anode material, Lithium ion batteries

Abstract: The $\mathrm{ZnMn}_{2} \mathrm{O}_{4}$ nanoplates were successfully prepared by a hydrothermal method and then a annealing process. The electrochemical properties of the $\mathrm{ZnMn}_{2} \mathrm{O}_{4}$ nanoplates as an anode material a reinvestigated for lithium ion batteries. The results shown that the $\mathrm{ZnMn}_{2} \mathrm{O}_{4}$ nanoplates exhibited a larger initial of $1223 \mathrm{mAh} \cdot \mathrm{g}^{-1}$ at a current density of $100 \mathrm{~mA} \cdot \mathrm{g}^{-1}$, still kept at 595 $\mathrm{mAh} \cdot \mathrm{g}^{-1}$ after 100 cycles. The enhanced electrochemical performance suggests the promising potential of the $\mathrm{ZnMn}_{2} \mathrm{O}_{4}$ nanoplates in lithium-ion batteries.

\section{Introduction}

High-power-capacity lithium-ion batteries (LIBs) have received increasing attention with the development of the microelectronics industry. Portable electronic devices and the upcoming electric vehicles need new power supplies with high energy density [1, 2]. Recently, mixed transition-metal oxides (MTMOs) have attracted increasing research interest worldwide [3, 4]. The MTMOs which can be designated as $\mathrm{A}_{\mathrm{x}} \mathrm{B}_{3-\mathrm{x}} \mathrm{O}_{4}$, have been investigated for lithium storage by some investigators [5]. $\mathrm{ZnMn}_{2} \mathrm{O}_{4}$ is particularly interesting because all the Co ions have been substituted by cheap and non-toxic $\mathrm{Zn}$ and $\mathrm{Mn}$ ions [6]. Interestingly, $\mathrm{ZnMn}_{2} \mathrm{O}_{4}$ can store $\mathrm{Li}$ ions through both conversion and alloying reactions because $\mathrm{Zn}$, one of the products of the conversion reaction, further alloys with Li to form LiZn [7].

In this paper, we report the synthesis of $\mathrm{ZnMn}_{2} \mathrm{O}_{4}$ nanoplates via a solvothermal carbon templating method and then a annealing process. As an anode material for LIBs, it shows excellent cyclability and rate capability.

\section{Experimental Details}

\section{Synthesis and characterization of the samples}

All chemicals were of analytical grade and were used without further purification. In a typical experiment, $0.5 \mathrm{mmol} \mathrm{MnAc}_{2} \cdot 4 \mathrm{H}_{2} \mathrm{O}$ and $0.25 \mathrm{mmol} \mathrm{ZnAc}_{2} \cdot 2 \mathrm{H}_{2} \mathrm{O}$ was dissolved in $30 \mathrm{~mL}$ deionized water at room temperature under magnetic stirring. Then $5 \mathrm{~mL}$ of $\mathrm{N}_{2} \mathrm{H}_{4} \cdot 4 \mathrm{H}_{2} \mathrm{O}(85 \%)$ was added into the above solution. The mixture was poured into and sealed in a Teflon-lined stainless steel autoclave of $50 \mathrm{~mL}$ capacity. The autoclave was heated to and maintained at $180^{\circ} \mathrm{C}$ for $12 \mathrm{~h}$ and then air-cooled to room temperature. The product was collected by filtration, washed with distilled water and ethanol, and then dried under vacuum at $60^{\circ} \mathrm{C}$ for $10 \mathrm{~min}$. The fresh sample now was ready for further processing and characterization. The obtained powders were heated in air at $500-700^{\circ} \mathrm{C}$ for $6 \mathrm{~h}$ (at a heating rate of about $4^{\circ} \mathrm{C} / \mathrm{min}$ ) to synthesize $\mathrm{ZnMn}_{2} \mathrm{O}_{4}$ nanoplates (denoted 
as ZMO-500, ZMO-600, and ZMO-700, respectively).

The crystallinity and structure of the samples were characterized by X-ray diffraction (XRD), using a Rigaku X-ray diffractometer with $\mathrm{Cu} \mathrm{K} \alpha$ radiation $(\lambda=1.5406 \AA)$. Scan electron microscopy (SEM) images were carried out with a LEO 1530VP (LEO, Germany) electron microscopy.

The electrochemical characterization was performed using CR2032 coin-type test cells. The cell consisted of a cathode with the composition of $70 \mathrm{wt} . \%$ active materials, $20 \mathrm{wt} . \%$ carbon black, and 10 wt.\% PVDF, a lithium metal anode separated by a Celguard 2400 microporous film. The electrolyte was $1 \mathrm{molL}^{-1} \mathrm{LiPF}_{6} /$ (EC) and (DEC) (1:1). The charge-discharge tests were galvanostatically performed over 0.01 to $3.0 \mathrm{~V}$ at different current densities.

\section{Results and discussion}

Figures 1 illustrates the XRD patterns the $\mathrm{ZnMn}_{2} \mathrm{O}_{4}$ samples. All diffraction lines in Fig. 1 can be indexed to the pure $\mathrm{ZnMn}_{2} \mathrm{O}_{4}$ (JCPDS card No. 71-2499). We can also see that the $\mathrm{ZnMn}_{2} \mathrm{O}_{4}$ nanoplates have good crystallinity through narrow peak width and high peak intensity as shown in XRD. No impurity phase was detected on the XRD patterns.

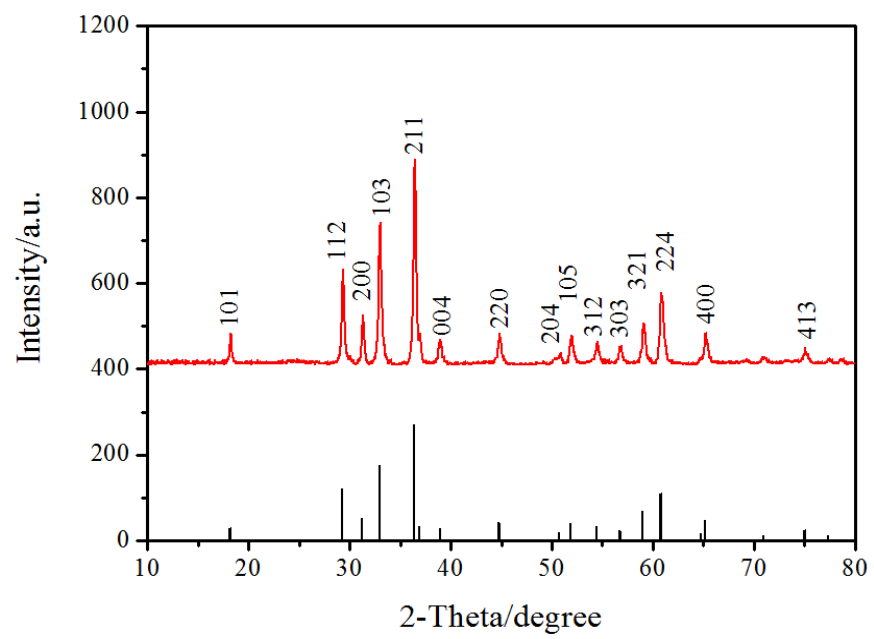

Fig. 1. XRD patterns of the $\mathrm{ZnMn}_{2} \mathrm{O}_{4}$ nanoplates samples.

In order to elucidate changes of the morphology of the $\mathrm{ZnMn}_{2} \mathrm{O}_{4}$ samples, Fig. 2 exhibited the SEM images for samples heat treated at the different temperatures. The SEM image reveals the microstructure of $\mathrm{ZnMn}_{2} \mathrm{O}_{4}$, as shown in Fig. 2, the product is composed of relatively irregular nanoplates with an average diameter of 1-3 $\mu \mathrm{m}$, and the thickness and the size of each edge of the nanoplates are 50 and $100 \mathrm{~nm}$, almost the same as that of nanoplates.

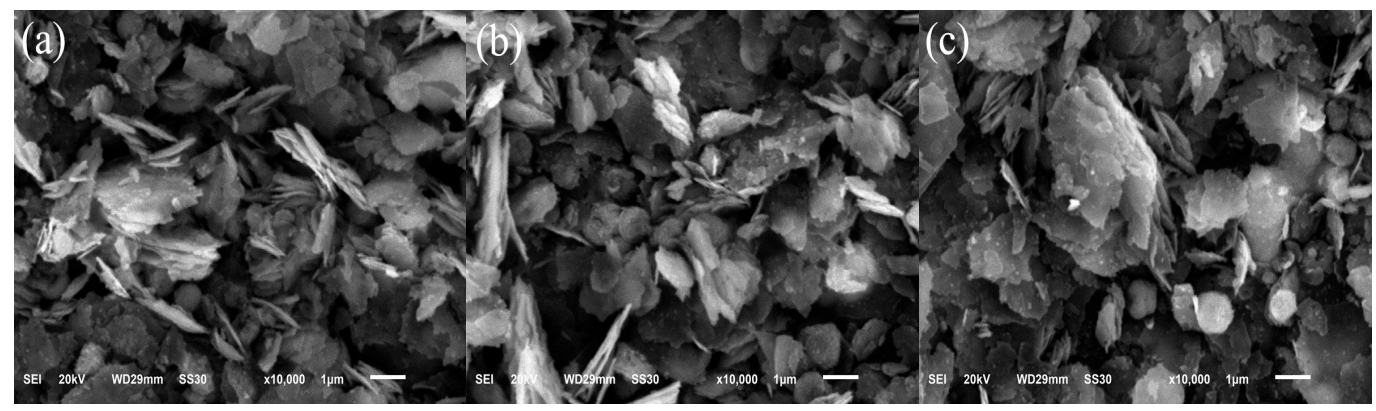

Fig. 2. SEM images of (a) ZMO-500, (b) ZMO-600, and (c) ZMO-700.

The electrochemical performances of $\mathrm{ZnMn}_{2} \mathrm{O}_{4}$ nanoplates were measured via coin cell testing. Fig.3 showed the typical discharge/charge cycles of the as-prepared ZMO-500, ZMO-600, and ZMO-700 electrodes cycled between 0.01 and $3.0 \mathrm{~V}$ with a current density of $100 \mathrm{~mA} \cdot \mathrm{g}^{-1}$ at room temperature, respectively. From these, a large irreversible capacity at the first cycle is observed. The 
specific capacity of the ZMO-500 and ZMO-700 showed an obvious decrease with cycling, from 1115 and $1150 \mathrm{mAh} \cdot \mathrm{g}^{-1}$ for the first cycle to 411 and $522 \mathrm{mAh} \cdot \mathrm{g}^{-1}$ for the $100^{\text {th }}$ cycle, whereas ZMO-600 exhibits the best performance for $\mathrm{Li}^{+}$insertion, the ZMO-600 delivers a larger initial capacity of $1223 \mathrm{mAh} \cdot \mathrm{g}^{-1}$ and shows a high reversible capacity of $730 \mathrm{mAh} \cdot \mathrm{g}^{-1}$ for the second cycle, which is much higher than what was reported for those samples. It still retains a high capacity of $537 \mathrm{mAh} \cdot \mathrm{g}^{-1}$, even after 50 cycles, and retains $595 \mathrm{mAh} \cdot \mathrm{g}^{-1}$ after 100 cycles, respectively. It is obvious that the ZMO-600 electrode shows much improved cycling performance with higher specific capacities at the same cycle with the same current density, as compared with the other samples, which may be attributed its bigger porous structure.

To better understand the electrochemical behavior of the ZMO-600, the ZMO-600 electrode was cycled at various current densities $\left(100-1000 \mathrm{~mA} \cdot \mathrm{g}^{-1}\right)$. The cell shows good rate capability with average discharge capacity of $1028,616,577,479,431$, and $331 \mathrm{mAh} \cdot \mathrm{g}^{-1}$ when the current density increased stepwise to $100,200,400,600,800$, and $1000 \mathrm{~mA} \cdot \mathrm{g}^{-1}$, respectively. Large surface area and the short diffusion length of spherical porous structured electrode can improve the kinetic properties of the lithium-ion during intercalation and easily delivers high discharge capacity even under extremely high currents. These results demonstrate that the $\mathrm{ZnMn}_{2} \mathrm{O}_{4}$ nanoplates has great potential as high-rate anode material in lithium-ion batteries.
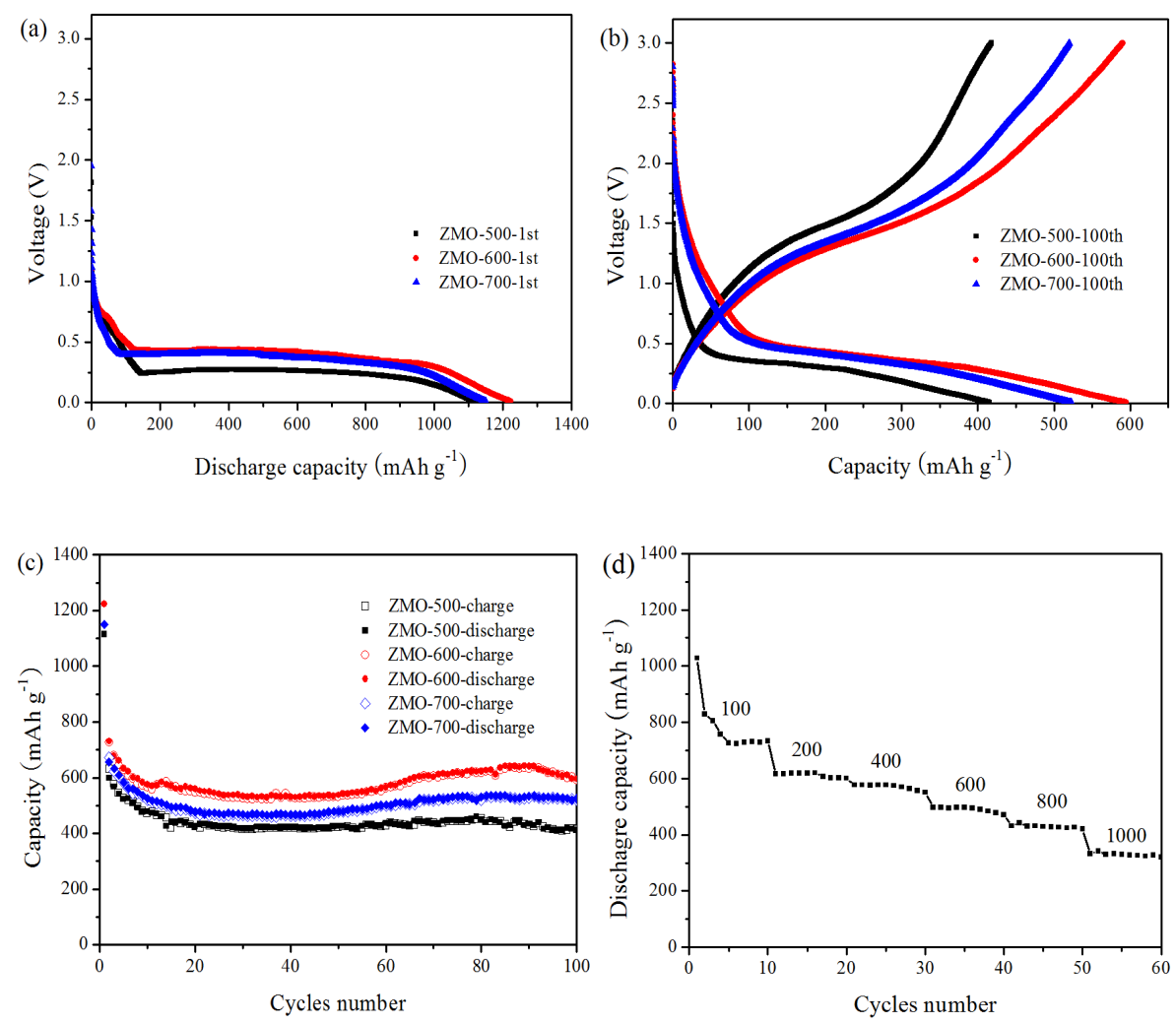

Fig. 3. (a) the first, (b) $100^{\text {th }}$ discharge/charge curves and (c) cycling performance of the ZMO-500, ZMO-600, and ZMO-700; (d) cycling performance of the ZMO-600 electrode at various current densities.

\section{Conclusions}

In summary, $\mathrm{ZnMn}_{2} \mathrm{O}_{4}$ nanoplates have been synthesized by a facile method. The ZMO-600 samples exhibited a high reversible capacity of $730 \mathrm{mAh} \cdot \mathrm{g}^{-1}$, it still retains a high capacity of 595 $\mathrm{mAh} \cdot \mathrm{g}^{-1}$, even after 100 cycles at a current density of $100 \mathrm{~mA} \cdot \mathrm{g}^{-1}$. These results clearly demonstrate that the $\mathrm{ZnMn}_{2} \mathrm{O}_{4}$ nanoplates have better electrochemical performance with high specific capacity, 
long cycle life, and good rate capability, indicating that they are promising candidates for LIB anodes.

\section{Acknowledgements}

This work were financially supported by the joint science and technology funds of Guizhou Science and Technology Department, Anshun city people's government and Anshun university (grant No. LKA [2013]17, LKA [2013]02).

\section{References}

[1] M. Armand and J.M. Tarascon: Nature 451 (2008), 652.

[2] R. Liu, J. Duay, and S.B. Lee: Chem Commun 47 (2011), 1384.

[3] Y. Ding, Y.F. Yang and H.X. Shao: Electrochimica Acta 56 (2011), 9433.

[4] S.W. Kim, H.W. Lee, D.H. Seo, D.K. Kim and K. Kang: Nano Research 4 (2011), 505.

[5] L. Zhou, H.B. Wu, T. Zhu and X.W. Lou: J MATER CHEM 22 (2012), 827.

[6] F.M. Courtel, H. Duncan, Y.A. Lebdeh, and I.J. Davidson: J Mater Chem 21 (2011), 10206.

[7] Y.Y. Yang, Y.Q. Zhao, L.F. Xiao and L.Z. Zhang: Electrochem Commun 10 (2008), 1117. 